\title{
Analysis and Research about Characteristics of Online Learning Behaviours of SPOC Learners
}

\author{
Qiang-Ping SONG ${ }^{1}$, Hai-Guang FANG ${ }^{1, a}$, Ying TENG ${ }^{2}$ and Bao-Cong JIAO' \\ ${ }^{1}$ Capital Normal University, Department of Educational Technology, Beijing, China \\ ${ }^{2}$ Capital Normal Universities, Department of Education, Beijing, China \\ a Corresponding author: fanghg2013@163.com
}

\begin{abstract}
SPOC (small private online course) has recently evolved into a typical representative in post-MOOC (massive open online courses) times. Current researches about SPOC mainly focus on blended learning mode, teaching process, and teaching mode etc., paying less attention to online behaviors of learners. Based on online platforms of the general knowledge course Game Theory, this paper analyzes and researches online behaviors of SPOC learners. In addition, this paper summarizes differences of SPOC and MOOC in online learning behaviors by collecting online learning behavioral data of 145 learners and investigating their online behavioral characteristics during their learning process. The research reveals, learners are fond of video media in terms of the communication form, tend to answer questions instead of coming up with their own questions in terms of interactions, and focus on quizzes and homework due to pressures of credits.
\end{abstract}

\section{Introduction}

SPOC (small private online course) emerges as a new concept which was forward after MOOC (massive open online courses) of the Harvard University [1]. In essence, SPOC and MOOC can be classified into the same category [2]. SPOC aims to realize organic combination of MOOC and class teaching [3]. Current researches only focus on blended learning mode [4], teaching process [5], and teaching mode [6]. Analysis about online learning behaviours of learnings mainly relies on the MOOC online research. At present, there are international comparative researches [7] about MOOC online behaviors and influence factors of MOOC learning behaviors etc. [8]. Different from thousands of learners in MOOC, SPOC limits the number of learners to dozens or several hundred at maximum. With regard to SPOC, its learning activities appear more flexible and efficient and its quizzes seem more rigorous [9]. Online learning behaviors of SPOC learners are different from those of MOOC. While drawing experience from current analysis about MOOC learning behaviors, this paper tries to carry out explanation and quantitative analysis about the general knowledge course Game Theory on basis of SPOC mode. This paper compared similarities and differences between online behaviors of SPOC and those of MOOC by analyzing and categorizing characteristics. At last, this paper predicts academic performance learners and summarizes characteristics of online learning behaviors.

\section{SPOC online learning behaviours}

\subsection{Brief Introduction to the Game Theory}

As a general knowledge course of a university, the Game Theory is available for learners who have completed mathematics program of a senior high school. The Game Theory on basis of SPOC combines online learning with offline face-to-face teaching. The course and its first lecture were put on "MOOC Platform of Chines Universities" in September, 2015. This course is updated every other week later on for 9 lectures. The offline faceto-face teaching lasts for 9 times in every other week. Details of the course are shown as the Table 1 .

Table 1. Basic information of the SPOC course Game Theory

\begin{tabular}{|c|c|c|c|}
\hline Faculty & $\begin{array}{c}\text { Teaching } \\
\text { Assistant }\end{array}$ & Credit & Attendant \\
\hline 8 Persons & 9 Persons & 2 & 145 Attendants \\
\hline
\end{tabular}

\subsection{Categorization of SPOC online learning behaviors}

The SPOC blended learning mode combines online learning with offline class and thus changes traditional class teaching mode of the Game Theory, bringing different learning experience to learners. The SPOC blended learning mode applied to Game Theory is shown in Figure 1. This paper discusses online links from perspectives of independent learning preparation, 
feedback and evaluation, as well as discussion and communication.

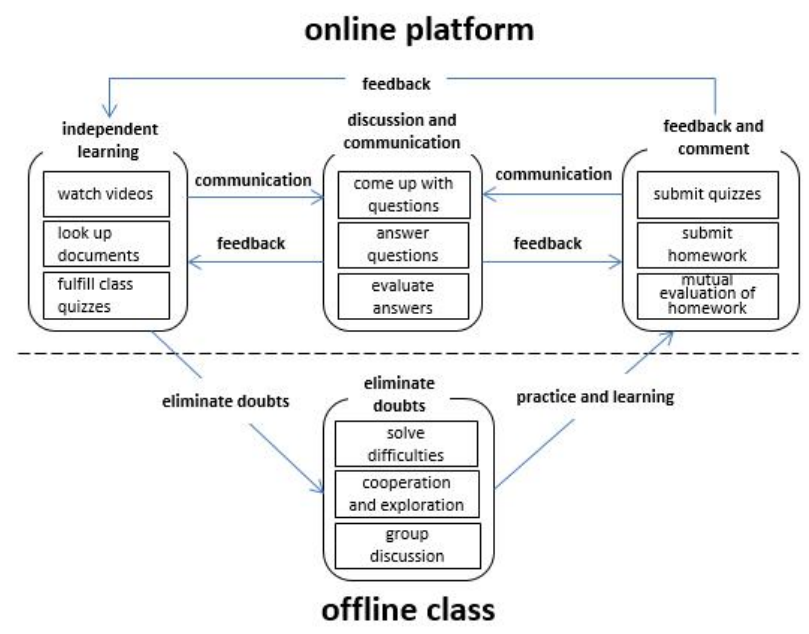

Figure 1. SPOC Blended Learning Mode of the Game Theory

According to implementation of SPOC of the Game Theory, this paper summarizes behavioral natures of online and office learning behaviors just as shown in Table 2. Independent learning refers to a process in which learners complete independent learning by using courseware resources offered by the platform. As an indispensable important link in learning. The feedback and comment mean the platform checks and recognizes the learning achievements and learning process through quizzes offered by it. The feedback and comment mainly include submission of homework, submission of quizzes, and mutual evaluation of homework. Discussion and communication refers to an exchange process between teachers and students on basis of the platform. Such interactions mainly include posting, replying, and commenting. Online discussion offers bases for preparation of offline face-to-face teaching.

Table 2. Learning mode, learning behaviors and natures of SPOC learners

\begin{tabular}{|c|c|l|}
\hline $\begin{array}{c}\text { Learning } \\
\text { Mode }\end{array}$ & $\begin{array}{c}\text { Learning } \\
\text { Behaviors }\end{array}$ & \multicolumn{1}{c|}{ Behavioral Natures } \\
\hline \multirow{4}{*}{$\begin{array}{c}\text { Independent } \\
\text { Learning }\end{array}$} & $\begin{array}{c}\text { Watching } \\
\text { Videos }\end{array}$ & $\begin{array}{l}\text { Video status (read or not } \\
\text { read), watching times, } \\
\text { playback times, watching } \\
\text { time }\end{array}$ \\
\cline { 2 - 3 } & $\begin{array}{c}\text { Look up } \\
\text { Documents }\end{array}$ & $\begin{array}{l}\text { Document status (review or } \\
\text { not review), looking-up } \\
\text { times, review times, looking- } \\
\text { up time }\end{array}$ \\
\cline { 2 - 4 } $\begin{array}{c}\text { Feedback } \\
\text { and }\end{array}$ & $\begin{array}{c}\text { Fulfill class } \\
\text { quizzes }\end{array}$ & $\begin{array}{l}\text { Homework status (submitted, } \\
\text { not submitted) }\end{array}$ \\
\cline { 2 - 4 } Comment & $\begin{array}{c}\text { Submit } \\
\text { quizzes } \\
\text { homework }\end{array}$ & $\begin{array}{l}\text { Submission time, quiz status } \\
\text { (submitted, not submitted), } \\
\text { score, times }\end{array}$ \\
\cline { 2 - 4 } & $\begin{array}{l}\text { Evaluate } \\
\text { each other's } \\
\text { status (submitted, not } \\
\text { submitted), score, times }\end{array}$ & $\begin{array}{l}\text { Time of mutual evaluation, } \\
\text { scores of mutual evaluation, } \\
\text { contents of mutual }\end{array}$ \\
\hline
\end{tabular}

\begin{tabular}{|c|c|l|}
\hline \multirow{4}{*}{$\begin{array}{c}\text { Discussion } \\
\text { and } \\
\text { Evaluation }\end{array}$} & $\begin{array}{c}\text { Come up } \\
\text { with } \\
\text { questions }\end{array}$ & $\begin{array}{l}\text { evaluation, and times of } \\
\text { mutual evaluation }\end{array}$ \\
\cline { 2 - 3 } & $\begin{array}{l}\text { Questions, frequency, times } \\
\text { of coming up with questions }\end{array}$ & $\begin{array}{l}\text { Answers, frequency, times of } \\
\text { qiving right answers, times of } \\
\text { giving wrong answers }\end{array}$ \\
\cline { 2 - 3 } & $\begin{array}{c}\text { Comments } \\
\text { on answers }\end{array}$ & $\begin{array}{l}\text { Contents, frequency, } \\
\text { commenting times, posts with } \\
\text { thumbs-up. }\end{array}$ \\
\hline
\end{tabular}

\section{Analysis about online learning behaviors of SPOC learners}

\subsection{Analysis about online learning behaviors}

\subsubsection{Independent Learning}

SPOC courseware resources for independent learning of the Game Theory consist of videos, documents (graphs and texts), and class quizzes. This paper collects statistical data about person-times of learning of 45 videos and 83 documents. Figure 2 shows the statistical distribution of person-times of video watching. The persons-times register 245 at maximum and pumps to 45 at minimum. Figure 3 shows the statistical distribution of person-times of document review. The person-times of document reviews posts 155 at peak and falls to 50 at bottom. The person-times of video watching and document review fluctuate to decline, which indicates learners' passions for independent learning decrease with progress of learning. As shown in Figure 2, this paper video watching prevails over document review in terms of times. This reflects learners expect knowledge can be displayed in form of videos.

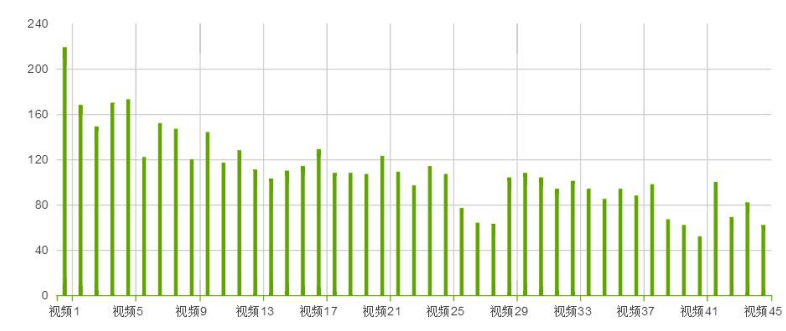

Figure 2. Statistical Distribution of Person-Times Of Video Watching

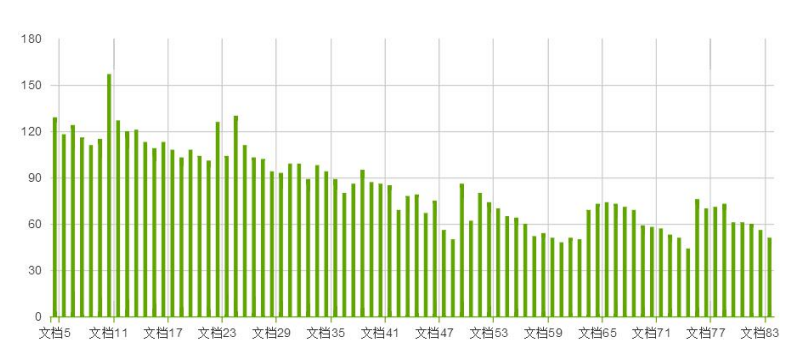

Figure 3. Document review statistical distribution of persontimes 


\subsubsection{Feedback and Comment}

The feedback and comment are mainly displayed in quizzes. Quizzes after every lecture consist of objective part and subjective part. The quizzes adopt automatic scoring system and the homework implements mutual evaluation mechanism. This paper counts attendants and average scores of quizzes and homework of these 9 lectures, just as shown in Figure 4. Except homework 3 and homework 9, attendants of other homework register $90 \%$ of all the students with an average score ranging from 75 to 85 . The data indicates attendance rate of quizzes and homework of every lecture is relatively high. Learners pay much attention to the feedback and comment, because such evaluation will influence their final score. According to the line chart, it can be found attendants decline in the third lecture and come to the bottom in the fourth lecture. This indicates learners require external supervision and intervention.

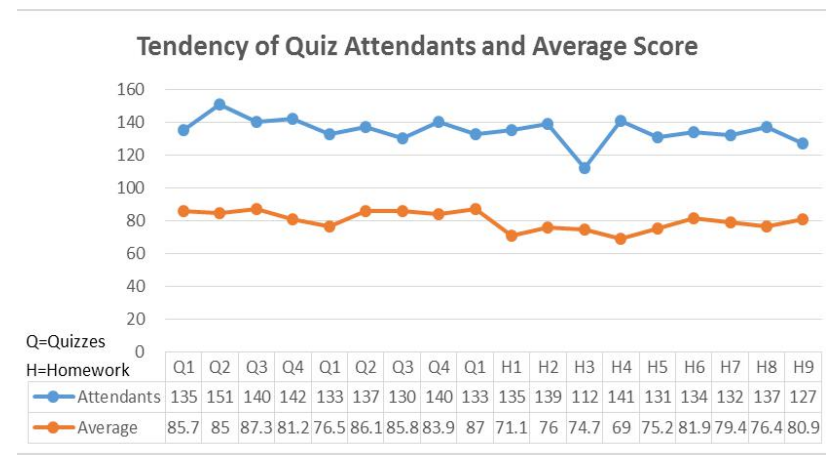

Figure 4.Tendency of Quiz Attendants and Average Scores

\subsubsection{Discussion and Communication}

This platform establishes several discussion sections for teachers and students to solve problems and exchange their ideas by posting, replaying, commenting and clicking thumbs-up. Every interaction can win thumbs-up of others. The background system can export the number of themes, replies, comments, posts, and thumbs-up of learners. The statistical data are shown in the following Table 3.

Table 3. Descriptive Statistical Data about Discussion and Communication

\begin{tabular}{|c|c|c|c|c|c|}
\hline & $\mathrm{N}$ & Min & Max & Mean & SD \\
\hline Themes & 145 & 0 & 34 & 2.37 & 4.633 \\
\hline Replies & 145 & 0 & 100 & 13.69 & 13.505 \\
\hline Comments & 145 & 0 & 27 & 1.59 & 4.294 \\
\hline Posts & 145 & 0 & 144 & 17.65 & 19.084 \\
\hline Thumbs-up & 145 & 0 & 118 & 6.67 & 13.298 \\
\hline Effective N & 145 & & & & \\
\hline
\end{tabular}

Posting times per capital in theme discussions is 2.37 with a maximum value of 34 and a minimum value of 0 . The mean value of total replies is 13.69. Students are highly involved in replies to theme discussions. The total number of comments refers to the times of commenting on replies of classmates. The mean value of total number of comments is 1.59 , lower than that of replies. Students tend to comment on theme discussions instead of posts of classmates. The mean value of the total number of posts is 17.65 and the mean value of posts in every lecture is 1.96. Involvement of students in the forum still needs to be improved. The mean value of thumbs-up is 6.67 and the thumb-up rate is $37.78 \%$. This reflects posts of some students are recognized by other classmates.

\subsection{Behavioral characteristics of online learners}

This paper summarizes four major characteristics of SPOC online learners by investigating details of practice and analyzing online behaviors of learners. These characteristics are respectively, easy start and difficulties in persistence, emphasis on videos instead of graphs, focus on quizzes instead of process, as well as stress on replies instead of comments

\subsubsection{Easy start and difficulties in persistence}

Learners are interested in SPOC online learning within first two weeks of the class. With further progress, learners reduce their times of watching videos and reviewing documents. During the implementation process, it takes us more time to sustain enthusiasm of learners and lower possibilities of stopping leaning instead of attract these learners just at the very beginning.

\subsubsection{Emphasis on videos instead of documents}

During the independent leaning process, learners pay much more time in watching videos than that in reviewing documents. Learners prefer videos during the process of explaining knowledge, because videos are characterized by rich contents, various sounds, and images of teachers. These elements can be easily received by learners. It is suggested to use videos as core elements and adopt documents as supplementary elements during the process of preparing independent learning courseware resources.

\subsubsection{Focus on quizzes instead of process}

Videos, discussions and videos aims to help student's master knowledge and gain better performance. However, these elements only occupy a small portion in final score. Students show less involvement in comparison with quizzes which take up a large portion in scores of learners. Quizzes show higher completion rate and involvement rate. It is advised to establish multiple and reasonable evaluation mechanisms during the SPOC practice process, 
so as to evaluate final learning achievements of students in a comprehensive way.

\subsubsection{Stress on replies instead of comments}

Learners tend to reply to posts during discussion and communication. It is obvious learners only replay to corresponding posts according to teaching instructions, failing to offer in-depth and positive comments on replies. This frustrates the mutual discussion and learning atmosphere. Teachers are supposed to guide students to come up with questions through independent thinking and comment on replies through sharing and communication mechanism.

\section{Relevance analyses}

\subsection{Analysis about the relevance of online learning behaviors}

Relationships between research behaviors can eliminate isolated views about occurrence of online leaning behaviors of SPOC learners. This paper uses Pearson relevance analysis method to explore the relevant of different behaviors, just as shown in Table 4.

Table 4. The Relevance of Various Elements of Online Learning Behaviors

\begin{tabular}{|c|l|l|l|l|l|l|l|}
\hline & Videos & $\begin{array}{c}\text { Watch- } \\
\text { ing }\end{array}$ & Themes & Replies & $\begin{array}{c}\text { Com- } \\
\text { ments }\end{array}$ & $\begin{array}{c}\text { Thumbs } \\
\text {-up }\end{array}$ & Quizzes \\
\hline Watching & $.732^{* *}$ & & & & & & \\
\hline Themes & $.185^{*}$ & $.276^{* *}$ & & & & & \\
\hline Replies & $.181^{*}$ & $.180^{*}$ & $.609^{* *}$ & & & & \\
\hline Comments & .048 & $.207^{*}$ & $.523^{* *}$ & $.395^{* *}$ & & & \\
\hline Thumbs-up & .137 & .169 & $.692^{* *}$ & $.789^{* *}$ & $.519^{* *}$ & & \\
\hline Quizzes & $.488^{* *}$ & $.613^{* *}$ & .164 & $.309^{* *}$ & .120 & $.199^{*}$ & \\
\hline Homework & $.345^{* *}$ & $.648^{* *}$ & $.239^{* *}$ & $.347^{* *}$ & .173 & $.257^{* *}$ & $.798^{* *}$ \\
\hline
\end{tabular}

Notes:: (1)**. significate relevant on both sides of 0.01 level.

(2). significant relevant on both sides of 0.05 level.

It can be found from this chart, the number of videos and the time of watching videos exceed 0.6. This illustrates online learning behaviors of independent learning have significant relevance. With regard to discussion and communication, the total number of themes, replies, and comments also shows significant relevance. In addition, the relevance between the total number of thumbs-up and that of replies registers 0.789 (significant relevance). The relevance between the total number of thumbs-up and that of comments posts 0.519 (medium relevance), also indicating relevance between replies and thumbs-up. For the feedback and comment, the relevance between quizzes and homework achieves
0.789 (significant relevant), reflecting the consistency of quiz scores and homework.

For independent learning, discussion and communication, the time of watching videos is less related to the total number of themes. In addition, it has no relevance with the total number of replies, comments and thumbs-up. Feedbacks and communication of learners share significant relevant with multiple behaviors. This indicates feedbacks and communication are closed related to online learning behaviors. This can be found through the significant relevance $(0.613)$ between quiz scores and the time of watching videos. The relevance between homework and the time of watching videos is 0.648 (significant relevance) and the relevance between homework score and the total number of posts is 5.42 (medium relevance).

\subsection{Regression analysis about online quiz scores}

This paper uses regression analysis method to conduct stepwise linear regression analysis about influence factors of SPOC online quiz scores. This analysis takes online quiz scores as independent variables and considers the number of videos, the time of watching videos, as well as the total number of themes, replies, comments, thumbsup and other online learning behaviors as dependent variables (predictive variables), just as shown in Table 5.

Table 5. Abstract of Stepwise Diversified Regression Analysis about Online Quiz Scores

\begin{tabular}{|c|c|c|c|c|c|}
\hline Model & $\mathrm{R}$ & R Square & $\begin{array}{c}\text { Adjusted } \\
\text { R Square }\end{array}$ & $\mathrm{B}$ & Beta \\
\hline (Constant) & & & & 55.958 & \\
\hline 1. Videos & .615 & .378 & .378 & 1.010 & .615 \\
\hline 2. Replies & .714 & .509 & .131 & .900 & .548 \\
\hline
\end{tabular}

Table 5 is the abstract of the regression analysis. Failing to achieve the standard of significant independent variables, the regression coefficient is excluded from the regression model. Only the number of videos and the total number of replies can be taken as significant variables of the regression model. The multiple relevance coefficients are 0.714 and the unified explanation variance of the two factors $\mathrm{R}$ Square is 0.509 . In other words, the two factors can be united to predict $50.9 \%$ of variables of scores. The explanation variance of the number of videos (Adjusted R Square) is 0.378 , namely $37.8 \%$. In addition, the explanation variance of the total number of replies (Adjusted R Square) is 0.131, namely $13.1 \%$. Therefore, the number of videos is a major influence factor for quiz scores and the total number of replies is a minor one. 


\section{Discussion and summary}

\subsection{Comparison of SPOC and MOOC online learning behaviors}

SPOC and MOOC show big differences in openness, student number, learning mode, evaluation form and learning cost [10] etc. These differences also lead to differences in online learning behaviors of learners. Based on previous researches about MOOC online learning behaviors, this paper compares differences of online behaviors of SPOC and MOOC learners.

\subsubsection{High involvement rate of SPOC learners in online learning activities}

For involvement rate, the data indicates the involvement rate of MOOC learners is $20 \%$ and the course completion rate of them is $4 \% .60 \%$ of above learners watch videos and $40 \%$ of above learners submit quizzes [11]. SPOC learners show higher involvement rate. Their forum involvement rate is $98 \%$ and the mean value of replies is 13.69 . The course completion rate of SPOC learners can register $95 \%$ and their video completion rate is $71 \%$. Quiz submission rate of every lecture is sustained above $85 \%$ and their average scores range from 75 to 85 .

\subsubsection{Online learning behaviors of SPOC learners are restrictive}

The research indicates, the more course MOOC learners take, the high possibility MOOC learners show to complete courses [12]. Due to pressures of credits, SPOC learners need to attend online learning independently. In addition, teachers can supervise and guide online learning behaviors of learners, which restrict their online learning behaviors.

\subsection{Suggestions for implementation of SPOC}

Through research about online learning behaviors of SPOC learners in the course Game Theory, this paper comes up with suggestions for construction and implementation of SPOC.

(1) Learners prefer to take videos as the manifestation form of learning contents. They are less involved in document review. During the development of SPOC, it is suggested to explain knowledge points by taking videos as major method and documents as a supplementary method.

(2) Learners tend to answer questions put forward by their classmates instead of themselves. During the implementation process, teachers should stimulate the ability of students to find questions and come up with questions by establishing a reward mechanism for coming up with questions.

(3) Due to pressures of credits, SPOC learners pay much attention to quizzes and homework contents. Other modules of SPOC courses are easily ignored. It is suggested to introduce diversified evaluation mechanisms for online score evaluation.

Research about online learning behaviors of SPOC learners can help us analyze contents and manifestation forms which attract attention of online learners. How to handle online learning and offline class will become a major topic for researches about SPOC.

\section{References}

1. S.Coughlan,(2013),http://www.bbc.com/news/busine ss-24166247.

2. Z.T. Zhu, M.Z. Liu, Open Education Research 20, 36 (2014)

3. W. Xu, Y.Z. Jia, A. Fox, Modern Distance Education Research 27, 13 (2014)

4. R. Chen, Z.M. Liu, Distance Education In China 34, $42(2015)$

5. B. He, Y. Cao, China Educational Technology 36, 22 (2015)

6. J.J. lv, Journal Of Distance Education 33, 72 (2015)

7. Y.F. Xue, Z.Z. Huang, F. Shi, Open Education Research 21, 80 (2015)

8. X. Fang, Open Education Research 21, 46 (2015)

9. A. Fox, COMMUN ACM 56, 38 (2013)

10. F.YLiu,http://epaper.heeact.edu.tw/images/epaper_h eeact_edu_tw/2014_0301_No48/P-40F1.png

11. Z.X. Jiang, Y. Zhang, X.M. Li, Comput Res Dev 58, $614(2015)$

12. M.L. LI, S.P. Xu, M.L. Sun, Open Education Research 21, 63 (2015) 